УДК 321.7

\title{
КОНСТИТУЦИОННАЯ КУЛЬТУРА И КУЛЬТУРА КОНСТИТУЦИИ: СООТНОШЕНИЕ ТЕОРИИ И ПОЛИТИЧЕСКОЙ ПРАКТИКИ В РАМКАХ КУЛЬТУРЫ ДЕМОКРАТИИ
}

\author{
Дьяченко Юлия Владимировна \\ кандидат политических наук, доцент \\ ФГБОУ ВО «Саратовская государственная юридическая академия»
}

Аннотация: В статье исследуются актуальные в русле современных политико-правовых процессов и явлений категории, в совокупности характеризующие как с точки зрения теоретических обоснований, так и с позиции политической практики, специфику демократической формы правления как наиболее успешной в современных условиях. Рассматриваются культурные основания политики, права и демократии, как объединяющего вектора развития значительной части современных государств.

Ключевые слова: конституция, демократическая политическая культура, конституционная культура, культура конституции, культура демократии.

\section{CONSTITUTIONAL CULTURE AND THE CULTURE OF THE CONSTITUTION: THE RELATIONSHIP BETWEEN THEORY AND POLITICAL PRACTICE WITHIN THE CULTURE OF DEMOCRACY}

\section{Dyachenko Yyliya Vladimirovna}

\begin{abstract}
The article examines the categories that are relevant in the context of modern political and legal processes and phenomena, which together characterize both from the point of view of theoretical justifications, and from the point of view of political practice, the specifics of the democratic form of government as the most successful in modern conditions. The article considers the cultural foundations of politics, law and democracy as a unifying vector of development of a significant part of modern states.
\end{abstract}

Key words: constitution, democratic political culture, constitutional culture, constitution culture, democracy culture. 


\section{ОБЩЕСТВО. ГОСУДАРСТВО. ЛИЧНОСТЬ: ПРОБЛЕМЫ ВЗАИМОДЕЙСТВИЯ В СОВРЕМЕННЫХ УСЛОВИЯХ}

Современные исследования общественной жизни в значительной степени направлены на изучение политических и правовых аспектов, поскольку именно данные векторы функционирования общества выступают наиболее значимыми в силу своей специфики. В совокупности политика и право формируют всю систему государственного и общественного взаимодействия на основе законов и границ, принимаемых и определяемых властью, а также выработанных механизмов их реализации и применения санкций за отклонение от их выполнения.

Основные элементы подобного взаимодействия закреплены в Основном законе государства - Конституции, следовательно, наряду с ознакомлением населения страны с самим документом как основополагающим во всей законодательной системе, важно формировать и повышать уровень восприятия гражданами содержания закона, осознания его значимости и эффективности с точки зрения регулирования общественных отношений, а, следовательно, и всей законодательной базы.

Подобные процессы возможны в случае того, что рассматривается не только соотношение конституционных (правовых) процессов и политической сферы, поскольку это и способствует оформлению порядка во всей общественной системе в целом. Выделенные аспекты, как показывает непосредственная политическая и правовая практика, проявляют себя наиболее успешно лишь с опорой на культурные основы общества. Культурная деятельность, по утверждению многих исследователей, является способом освоения и подчинения человеку политической и конституционной (правовой) реальности, что свидетельствует об их тесной связи [1, с. 60].

Тесное взаимодействие культуры и политико-правовой сферы наиболее ярко выражено в рамках демократического режима, поскольку становится возможным только в рамках относительно свободных взаимоотношений между властью и обществом, между ветвями власти, между гражданами по поводу политики и права, а также иных сторон жизни общества. Кроме того, рассмотрение подобного взаимодействия позволяет исследовать данный аспект не только с точки зрения государственных институтов и правовых систем, но и с учетом человеческого фактора. Последнее также наиболее характерно именно для демократии, предполагающей значительные возможности для участия граждан государства в принятии важных политических решений, в том числе и законов. Из подобного общего правила ряд авторов вывели понятие 


\section{ОБЩЕСТВО. ГОСУДАРСТВО. ЛИЧНОСТЬ: ПРОБЛЕМЫ ВЗАИМОДЕЙСТВИЯ В СОВРЕМЕННЫХ УСЛОВИЯХ}

«демократическая конституционная культура», которая выступает неотъемлемой частью общечеловеческой и национальной культур [2].

В большей части современных государств существуют Основные законы (конституции, конституционные акты, декларации, хартии), и их детальное изучение показывает сильное влияние на формулирование их текстов культурных традиций и особенностей конкретной страны. В частности, конституционные акты парламентских монархий имеют ряд отличительных черт от конституций республик, а те, в свою очередь, не включают в тексты положения, характерные для теократических монархий (как, например, Саудовская Аравия, ОАЭ, Катар и др.), основанных в основном на священных книгах как источниках права.

Вместе с тем, общим для всех упомянутых выше законов будет выступать то, что современные глобальные процессы привели к необходимости более существенных изменений в содержании документов, в частности, в расширении демократических принципов (даже в монархиях, что сегодня мы можем видеть на практике). Помимо этого, важным становится усиление культурного фактора в общественной жизни как отдельно взятых государств, так и всего мирового сообщества в целом. Последнее приобрело значимость в силу того, что одно наличие в стране конституции не свидетельствует о высоком уровне политической и конституционной культуры, что является одним из главных принципов демократии. Необходимым стало повышение уровня восприятия населением законов и правил поведения в обществе, а также их гарантированности и обеспечения.

Как уже упоминалось выше, конституция страны должна выступать отражением всех ее особенностей (духовных, экономических, социальных), включать все глубинные, устойчивые ценности общества, передаваемые из поколения в поколение на протяжении веков. Не менее значимым должны стать закрепленные в Основном законе гарантии стабильной, надежной защиты и воспроизводства указанных ценностей. При этом каждое последующее поколение, принимая их, переосмысливает и видоизменяет, подстраивая под требования современного им общественного (конституционного) устройства. Исходя из этого, можно сделать вывод, что конституция порождается культурой, сформированной и проявляющейся в отдельно взятом обществе и государстве.

На основе выделенных особенностей взаимодействия культуры и политико-правовой (конституционной) составляющей общественной жизни 


\section{ОБЩЕСТВО. ГОСУДАРСТВО. ЛИЧНОСТЬ: ПРОБЛЕМЫ ВЗАИМОДЕЙСТВИЯ В СОВРЕМЕННЫХ УСЛОВИЯХ}

можно выделить следующие понятия. «Конституционная культура» представляет собой созданную опытом многих поколений систему ценностей и убеждений, определяющих основные демократические правила и принципы, которые, в свою очередь, установлены и гарантированы общественным согласием. Другими словами, конституционная культура исторически обусловлена и имеет двойственную политико-правовую природу. Именно она отображает выработанное веками и поколениями восприятие конституции как главного закона страны и как правового документа, и как регулятора основных общественных политических процессов на основе культурного опыта.

В отличие от данного понятия «культура Конституции» позволяет выявить уровень данного общественного согласия и, соответственно, осознания населением страны значимости данного закона как основополагающего во всех общественных взаимоотношениях.

Конституционная культура в каждой стране складывается веками и опирается на предшествующий законодательный (конституционный) опыт. Исходя из этого, в ее системе общественного взаимодействия складываются определенные правила поведения органов публичной власти, ее должностных лиц и граждан по отношению к тексту Основного закона, а не просто формулируются положения текста с необходимыми терминами, а также набором значимых ценностей. Формируются взаимообратные отношения: с одной стороны, общественная жизнь в государстве складывается на основе детально прописанных в конституции норм и правил, исходя из его культурной специфики (конституционная культура), с другой, - граждане понимают и принимают (или наоборот не принимают) данные положения и сами ценности, обозначенные в законе (культура конституции).

Конституционная культура и культура конституции проявляются в различных направлениях общественной жизни. Они находят свое отражение в принятых обществом нормах и правилах (оформленных в виде законов и других правовых актов), в политической системе государства, в деятельности политических институтов и органов власти, их отношениях между собой и с гражданами государства, в общественном статусе личности и др. Именно они определяют уровень формирования и развития демократических ценностей в той или иной стране.

На государственном уровне конституционно-правовые ценностные системы, сформированные на протяжении длительного времени несколькими поколениями, включают всю систему правовых норм, традиций и обычаев, 


\section{ОБЩЕСТВО. ГОСУДАРСТВО. ЛИЧНОСТЬ: ПРОБЛЕМЫ ВЗАИМОДЕЙСТВИЯ В СОВРЕМЕННЫХ УСЛОВИЯХ}

лежащих в основе качеств самобытности и идентичности страны. Конституционная культура предполагает обеспечение разумного развития общечеловеческих ценностей в рамках всей страны, а культура конституции их разумное и эффективное соотношение с государственными особенностями на уровне отдельно взятой личности для обеспечения необходимой среды развития данного конкретного общества.

Соотношение двух выявленных выше категорий находит отражение в самостоятельном явлении политико-правовой (конституционной) и культурной сторон общества - «культуре демократии», под которой мы будем понимать уровень осуществления в демократическом государстве принципов конституционализма как основополагающего: юридическое отражение в Основном законе (Конституции) наиболее существенных правил и норм поведения в обществе и фактическая их реализация в общественной и политической практике в контексте ее признания гражданами государства (ее легитимность). Применительно к данному понятию В.С. Рахманин отмечает, что «онтологией культуры демократии является многообразие различных культур в обществе и их способность к взаимодействию. Вне такого многообразия культур и их взаимообогащающейся коммуникации демократия не формируется и не существует» [3, с. 261], что подтверждает наши доводы.

По мнению отдельных авторов, гармоничность такой ценностной среды (основанной на понимании, осознании значимых для общества ценностей большей частью населения) и определяется верховенством Конституции как главного юридического документа страны [4; 5, p. 3]. Именно главенство данного закона приводит к тому, что конституционные нормы и правила все больше охватывают правовое и политическое сознание граждан страны, политическую и правоприменительную практику, что в результате сформирует образ жизни всего населения.

Вместе с тем, любой закон, и прежде всего основной, сможет реализовать прописанные в нем положения, предоставить и защитить закрепленные права и свободы человека и гражданина только в том случае, если в своей основе будет ориентироваться, прежде всего, на личность с ее социальной сущностью, степенью осознания себя гражданином и членом данного общества, высоким уровнем политической и правовой культуры, а также стремлениями к реализации своих интересов и потребностей. Только в данном случае можно с уверенностью утверждать о развитии конституционной культуры в государстве, культуры конституции и всей культуры демократии в целом. 


\section{Список литературы}

1. Баталов Э. Политическая культура демократии // Российская Федерация. - 1995. - №5. - С.59-62.

2. Арутюнян Г. Г. Конституционная культура XXI века и новые вызовы системного развития конституционной юстиции / Доклад на Международной конференции в Сеуле 4 сентября 2008 г. URL: htpp://www.concourt.am/armenian/ structure/president/articles/korea2008_ru.pdf.

3. Рахманин В.С. Диалог политических культур как демократический процесс / Логос. - 2005. - №4. - С. 259-268.

4. Арутюнян Г.Г. Формирование конституционной культуры в России и ее значение для развития конституционализма в странах молодой демократии / Выступление в Кремле на конференции, посвященной пятнадцатилетию принятия Конституции Российской Федерации 12.12.2008 г. URL: htpp://www.concourt.am/armenian/structure/president/articles/moscow2008.pdf.

5. Dworkin R. Constitutionalism and Democracy // European Journal of Philosophy. - 1995. - Vol.3. - №1. - P.2-11. 